\title{
Development of Striatal Compartmentalization Following Pre- or Postnatal Dopamine Depletion
}

\author{
Abigail M. Snyder-Keller \\ Wadsworth Center for Laboratories and Research, New York State Department of Health, Albany, New York 12201-0509
}

Nigrostriatal dopamine (DA) projections terminate in distinct patches during the late prenatal and early postnatal period in the rat. During the first postnatal week, patches of DA fibers overlap with clusters of striatal neurons that share several identified characteristics. The early segregation of striatal cell types into either these patches or the surrounding matrix becomes a permanent organizational feature of the striatum. In order to determine whether the heterogeneous distribution of DA influences the formation of cellular patches, the developmental organization of chemically identifiable cell types was examined in normal rats and in rats DA depleted as infants ( 0 or $3 \mathrm{~d}$ ) or in utero (embryonic days 17-18). During the first postnatal week, corresponding patches of DA afferents and substance P (SP)-immunoreactive neurons existed in the striatum of normal animals, and AChE-positive zones overlapped these patches in the lateral striatum. Injection of 6-hydroxydopamine into the lateral ventricles of fetal or infant rats produced a dramatic loss of striatal DA terminals. Neither the patchy distribution of SP. immunoreactive neurons nor the distinctive pattern of AChE staining present during the first 2 postnatal weeks was disrupted. During the third postnatal week, cells immunoreactive for leu-enkephalin or calbindin- $D_{28 k}$ were confined to the matrix compartment, and this compartmentalization was also not noticeably changed by pre- or postnatal DA depletion. In adult animals, overlapping patches of leu-enkephalin- and SP-immunoreactive fibers were observed, regardless of whether any DA terminals remained. Thus, the basic organization of the striatal patch and matrix compartments develops normally in the absence of DA innervation through much of the formative period. Although these observations do not completely dismiss the possibility that the first DA afferents to appear in the striatal primordia influence contacted striatal cells to develop the patch phenotype, they suggest that the patchy distribution of DA afferents may be secondary to the early clustering of striatal neurons forming the patch compartment.

\footnotetext{
Received Apr. 17, 1990; revised Sept. 27, 1990; accepted Oct. 24, 1990.

I wish to thank Ms. Johanna Orlowski for her expert technical assistance and Drs. Anne Messer and Richard W. Keller, Jr. for their helpful comments pertaining to the manuscript. I am grateful to Dr. Gord Fishcll for advicc concerning the prenatal injection procedure and to Dr. Sylvia Christakos for her gift of calbindin$\mathrm{D}_{28 \mathrm{k}}$ antisera. This work was supported by NIH Grant MH45342 and by the Tourette Syndrome Association.

Correspondence should be addressed to Abigail M. Snyder-Keller, Wadsworth Center for Laboratories and Research, NY State Department of Health, P.O. Box 509, Alhany, NY 12201-0509.

Copyright (C) 1991 Society for Neuroscience $0270-6474 / 91 / 110810-12 \$ 03.00 / 0$
}

The compartmentalization of neuroactive substances into patch and matrix regions is now a well-established feature of the mammalian striatum. Neurons intrinsic to the striatum contain a variety of peptides, as well as GABA, and receive innervation from the substantia nigra, dorsal raphe, and cortex that is primarily dopaminergic, serotonergic, and glutamatergic, respectively (Graybiel and Ragsdale, 1983). Immunohistochemical studies have demonstrated that nearly all of the identified substances have been found either to be concentrated within regions described as "striosomes" (Graybiel and Ragsdale, 1978) or "patches" or to strictly avoid them, localizing instead to the surrounding "matrix" (Graybiel et al., 1981b; Gerfen, 1984, 1985; Bcckstcad and Kcrscy, 1985). This patch/matrix organization is a permanent feature of the striatum that is likely to form the basis for information processing in this structure (Gerfen, 1988).

Less is known about the development of this compartmentalization. Dopaminergic afferents had been noted to distribute in a patchy fashion within the striatum of neonatal animals (Olson et al., 1972; Graybiel et al., 1981a). Subsequent studies found that the organization of dopamine (DA) fibers into patches occurred 2-3 d prior to birth (Moon Edley and Herkenham, 1984). More recently, the striatal neurons were found to assume a patchy distribution prenatally, as well. Substance $P(\mathrm{SP})$ neurons are found in patches during late fetal development in the mouse (Ni and Jonakait, 1988), and neurons expressing $\mathrm{Ca}^{2+}$ calmodulin (CAM)-dependent protein kinase II (Newman-Gage and Graybiel, 1988) and dopamine- and cyclic adenosine 3':5'monophosphate-regulated phosphoprotein (DARPP-32) (see Foster et al., 1987) are also found in patches in the prenatal rat brain. Cells rich in DA D1 receptors (Murrin and Zeng, 1989) and opiate (Moon Edley and Herkenham, 1984; Murrin and Ferrer, 1984; van der Kooy, 1984) and muscarinic (Nastuk and Graybiel, 1985) ligand-binding sites also form clusters. In each case, examination of the overlap between DA fiber patches and patches of striatal neurons revealed by any of these markers revealed a close correspondence.

The question of which comes first has been addressed only by comparing the first appearance of each of these markers and the time at which they first are seen to form patches. Dopaminergic afferents are distributed initially in a homogeneous fashion, becoming clustered at about embryonic days 19-20 (E19-20) in the rat (Moon Edley and Herkenham, 1984; Voorn et al., 1988). The same homogeneous-to-patchy progression of patches of opiate-binding sites follows 1-2 d later (Moon Edley and Herkenham, 1984). However, 2 more recent studies have indicated that striatal neurons expressing DARPP-32 (Foster et al., 1987) or $\mathrm{Ca}^{2+} / \mathrm{CAM}-d e p e n d e n t$ protein kinase II (Newman- 
Gage and Graybiel, 1988) are clustered prior to the emergence of DA patches. The present studies were designed to directly test the possibility that DA afferents play a role in directing or consolidating the striatal patch/matrix organization by examining the development of various neuronal phenotypes in the brains of animals given intracerebral DA-depleting brain lesions prior to the emergence of DA patches. The role of DA in the maintenance of compartmentalization was also studied in animals DA-depleted either pre- or postnatally.

\section{Materials and Methods}

Animals. Female Sprague-Dawley rats (Griffin Labs, NY State Department of Health) were time mated; vaginal smears were taken to verify the exact date of sperm positivity, which was considered embryonic day (E) 0 . The offspring were examined at E17-19, or at various postnatal (P) ages after normal deliveries. All animals were perfused intracardially with a phosphate-buffered saline (PBS) rinse followed by $4 \%$ paraformaldehyde in $0.1 \mathrm{~m}$ phosphate buffer ( $\mathrm{pH}, 7.3)$. For young animals, $1 \%$ paraformaldehyde was included in the PBS rinse, whereas $0.5 \%$ sodium nitrite was included for older animals. After perfusion for 5-15 min, the brains were removed and immersed in the same fixative for an additional 4-24 hr (longer postfix times for younger tissue). Brains were rinsed in $15 \%$ sucrose in $0.1 \mathrm{M}$ phosphate buffer for at least $8 \mathrm{hr}$ prior to sectioning. The brains of animals $12 \mathrm{~d}$ of age or younger were embedded in an egg yolk matrix hardened by exposure to formalin vapors. This procedure confers added stability to immature brains, allowing sections to be cut at the same thickness as those from older brains. In pilot studies, it was determined that the embedding procedure did not compromise the immunocytochemical staining, as compared to nonembedded or cryostat-cut tissue.

Lesions. In order to deplete striatal DA, 107 fetuses at E16-18 and 70 neonatal rat pups (P1 or $\mathrm{P} 3$ ) were given intraventricular injections of 6-hydroxydopamine (6-HDA; Sigma Chemical Co.). For prenatal administration, this involved anesthetizing the pregnant female with ether and externalizing each uterine horn in turn. The head of each fetus was visualized through the uterine wall, and 6-HDA $(100-120 \mu \mathrm{g}$ of the base in $0.1 \%$ ascorbic acid $/ 0.9 \%$ saline) was injected through a 30 -gauge needle directed at the ventricular space in the center of the head. The full amount $(8 \mu \mathrm{l})$ was injected to 1 side of the midline suture. After removal of the needle, cyanoacrylic adhesive was used to seal the puncture in the uterine wall. Because the chances of inducing a miscarriage or stillbirth delivery are related to the amount of manipulation of the fetuses, only the 5 or 6 most readily accessible fetuses were injected per litter. A total of 20 litters were injected: 5 at E16, 10 at E17, and 5 at E18. Most females were allowed to give birth normally; however, only 5-6 pups were born to dams undergoing surgery at E16 (normal litter size is $10-15$ pups), and the lack of DA depletions in the remaining pups indicated that all treated fetuses had died in utero. A pup survival rate of $30 \%$ and $67 \%$ was obtained following operations at E17 and E18, respectively (including 4 litters lost by miscarriage or resorption), leaving a total of 36 prenatally lesioned rats. Lesioned pups could usually be identified by a slight reduction in body weight compared to their untreated littermates. When problems were detected in the delivery process, probably due to a twisting of one or both uterine horns, pups were delivered by cesarian and cross-fostered to a female time mated to give birth on the same day.

Postnatal 6-HDA injections were made $30 \mathrm{~min}$ following the administration of desmethylimipramine $(25 \mathrm{mg} / \mathrm{kg}$, s.c.; Merrell-Dow Research Institute), in order to protect noradrenergic neurons from the destructive effects of 6-HDA (Breese and Traylor, 1971). Bilateral injections of $5 \mu \mathrm{l} 6$-HDA (60 $\mu \mathrm{g}$ each side) or the vehicle solution $(n=$ 22) were made $1 \mathrm{~mm}$ lateral to the midline under ice anesthesia. Injections at P3 have previously been shown to result consistently in a 98$99 \%$ loss of striatal DA determined by biochemical methods (Stachowiak et al., 1984), and P1 injections have proven even more effective.

Animal procedures were approved by the Institutional Animal Care and Use Committee.

Immunocytochemistry. Thirty-micron frozen sections were cut on a sliding microtome and collected in $0.1 \mathrm{M}$ phosphate buffer. Chosen sections were rinsed briefly in $0.4 \%$ Triton X-100 in $0.1 \mathrm{~m}$ PBS (except for embedded material), then transferred to a solution of $0.2 \%$ Triton in PBS containing 5\% normal goat serum to block nonspecific antibody binding. Sections then were incubated free floating for $40 \mathrm{hr}$ at $4^{\circ} \mathrm{C}$ in

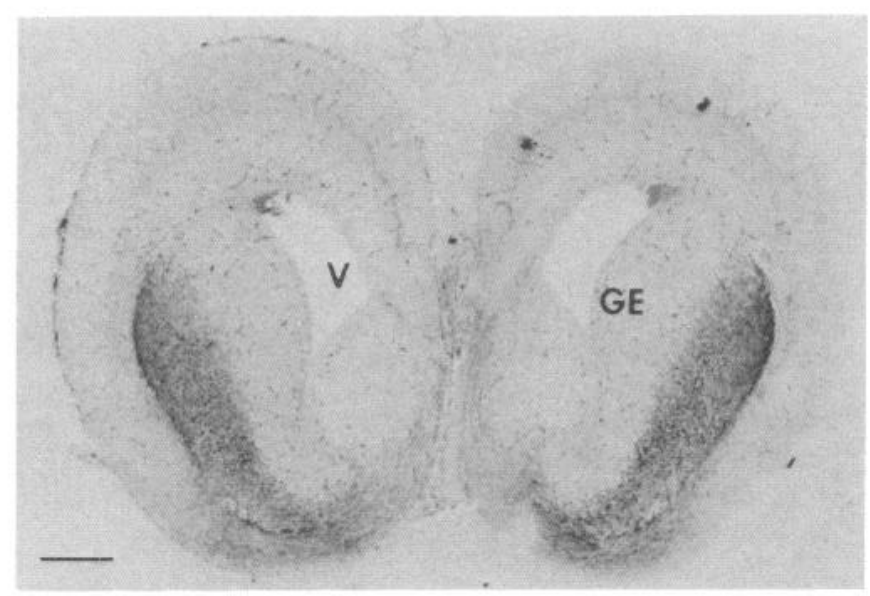

Figure 1. Initial development of nigrostriatal DA projections: A coronal section through the forebrain of an immersion-fixed brain from an E19 fetus, showing TH-immunoreactive fibers distributed homogeneously throughout striatum. $V$, lateral ventricle; $G E$, ganglionic eminence. Scale bar, $500 \mu \mathrm{m}$.

wells containing the appropriate antisera diluted in $0.2 \%$ Triton $/ 2.5 \%$ normal goat serum in PBS. Dopaminergic neurons were revealed with an antibody directed against tyrosine hydroxylase (TH; Eugene Tech; 1:6000), the synthetic enzyme for catecholamines. Antibodies to substance P (SP; Eugene Tech; 1:2000) and leucine-enkephalin (l-Enk; Incstar; $1: 1600$ ) were applied to adjacent sections. Antibodies to calbindin$D_{28 k}(1: 1200)$ were graciously supplied by Dr. Sylvia Christakos. After rinsing, sections were incubated in a goat anti-rabbit secondary antibody conjugated to biotin, followed by an avidin-biotin complex linked to peroxidase (Elite ABC kit, Vector Labs). A final incubation in $0.05 \%$ diaminobenzidine containing $0.0015 \% \mathrm{H}_{2} \mathrm{O}_{2}$ and $0.25 \%$ nickel ammonium sulfate revealed dense black staining of immunoreactive structures. Sections were mounted onto slides coated with chrom-alum gelatin, dehydrated, and coverslipped with Histoclad (Clay Adams). Observation and photomicrography of the sections were done on an Olympus AH-2 photomicroscope.

Tissue from lesioned animals was always processed together with at least 1 control that was perfused at the same time. This was especially critical for assessing the extent of residual DA innervation in prenatally lesioned animals (see Fig. 3, caption). Controls for nonspecific staining included omission of the primary antibody and performing the immunocytochemical procedure using antisera (SP or l-Enk) that were previously incubated with the appropriate antigen ( $1 \mathrm{mM}$; Sigma) in the presence of bacitracin $(100 \mu \mathrm{g} / \mathrm{ml}$; Penny et al., 1986). No specific staining was obtained following these procedures.

Acetylcholinesterase histochemistry. AChE histochemistry was performed according to the protocol of Levey and associates (Levey et al., 1983). Sections previously mounted and dried on slides coated with chrom-alum gelatin were immersed in $200 \mathrm{ml}$ of a solution containing $1.36 \mathrm{gm}$ sodium acetate, $100 \mathrm{mg}$ copper sulfate, $150 \mathrm{mg}$ glycine, $14 \mathrm{mg}$ ethopropazine, and $232 \mathrm{mg}$ acetylthiocholine, adjusted to $\mathrm{pH} 5.0$ with the addition of glacial acetic acid. Tissues were incubated for $90 \mathrm{~min}$, followed by brief rinsing in water and reaction for $1 \mathrm{~min}$ in sodium sulfide $(1.92 \mathrm{gm}$ in $200 \mathrm{ml}$ water adjusted to $\mathrm{pH} 7.8$ with $10 \mathrm{~N} \mathrm{HCl})$. After brief rinsing, staining was intensified by immersion for $1 \mathrm{~min}$ in $1 \%$ silver nitrate. Sections were dehydrated and coverslipped with Histoclad.

\section{Results}

\section{Prenatal development of DA afferents and SP neurons}

E17-19. Three to $4 \mathrm{~d}$ prior to birth, a dense band of THimmunoreactive fibers was observed in the lateral half of the striatum (Fig. 1). The origin of this DA innervation could be traced to the substantia nigra in sagittal sections. From E17 to E19, the nigrostriatal DA innervation appeared homogeneous in its distribution. Incubation of adjacent sections in SP antisera 

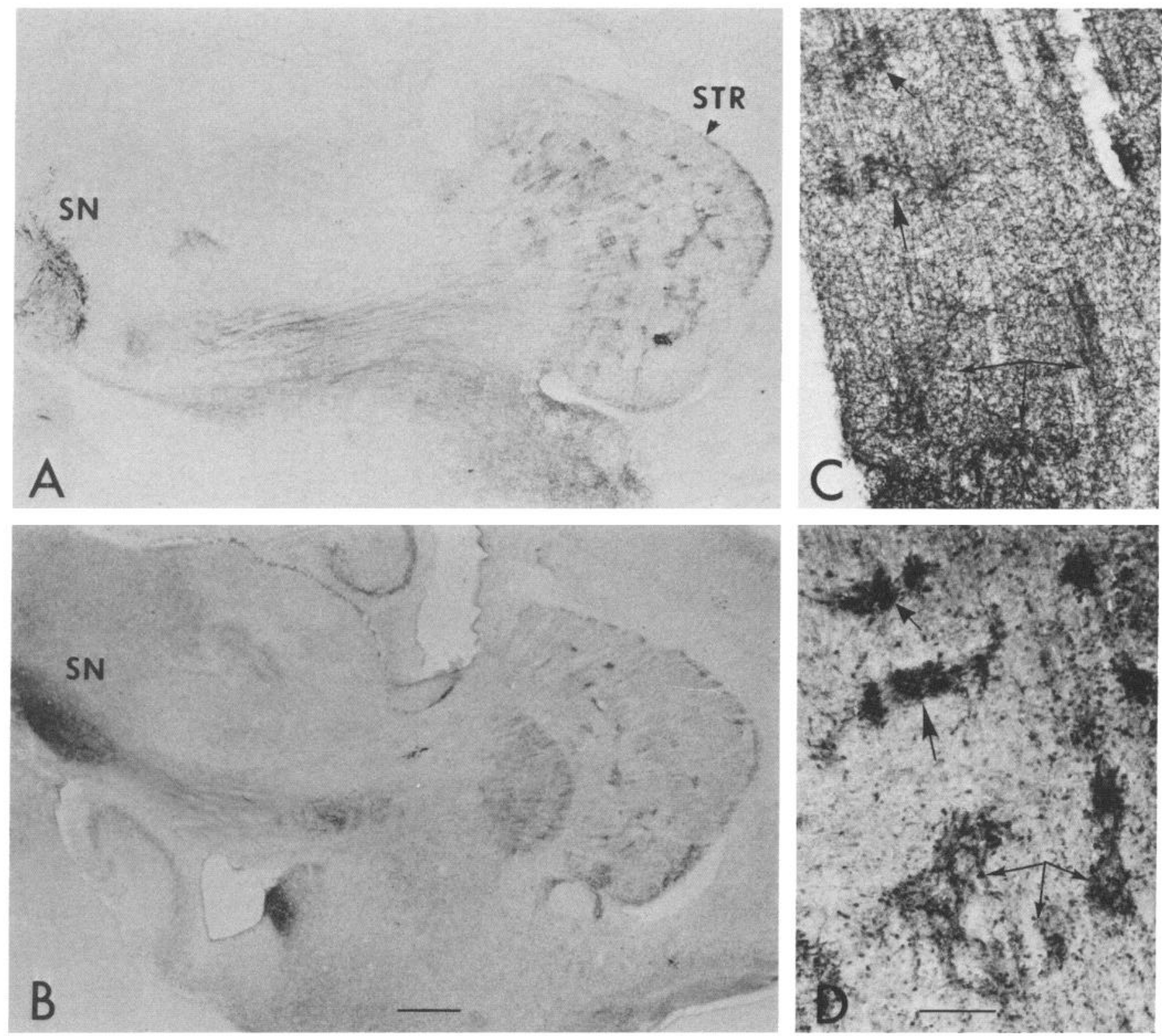

Figure 2. Postnatal distribution of TH- and SP-immunoreactive elements. $A$, TH-immunoreative cells and their projections to patches in the striatum $(S T R)$ in a sagittal section from a normal rat at P2. B, Patches of SP-immunoreactive striatal neurons and SP-immunoreactive fibers projecting to the substantia nigra $(S N)$ in a section taken from the same animal. Scale bar, $500 \mu \mathrm{m}$ for $A$ and $B$. $C$, High-power photomicrograph of TH-immunoreactive fiber patches taken from a sagittal section from a $\mathrm{P} 0$ rat striatum. $D$, SP-immunoreactive cells in a section adjacent to $C$. Arrows point to corresponding TH- and SP-immunoreactive fiber patches. Scale bar, $100 \mu \mathrm{m}$ for $C$ and $D$.

did not lead to specific staining of striatal elements, though nigral SP innervation was apparent at E19.

$P 0-2$. The first few days after birth (which occurred at E2122), dense patches of DA fibers were visible on a background of lower innervation density in unlesioned animals (Fig. $2 A$ ). SP-immunoreactive neurons were now obvious and were found in distinct clusters that approximated the size of the DA patches (Fig. 2B). Examination of adjacent sections revealed a partial overlap between patches of DA terminals and SP neurons, especially notable in sagittal sections (Fig. $2 C, D$ ).

Effects of prenatal 6-HDA. In animals given intracerebroventricular 6-HDA injection on E17-18, varying degrees of DA depletion were apparent. This variability was confirmed by pre- liminary biochemical measurements in $6 \mathrm{P} 0$ and $6 \mathrm{P} 18$ striata, which resulted in DA depletions ranging from $10 \%$ to $96 \%$ (R. W. Keller and A. M. Snyder-Keller, unpublished observations). Using TH immunocytochemistry, it was possible to reveal the distribution of remaining DA fibers, which in the case of complete lesions, were found only in the ventralmost aspect of the striatum surrounding the anterior commissure, as well as in the nucleus accumbens and olfactory tubercle. An example of a complete striatal denervation in an animal killed shortly after birth is shown in Figure $3 A$ (cf. Fig. $2 A$ ). A few surviving dopaminergic neurons were present in the midbrain, and in coronal sections taken from other animals, these were found to lie primarily in the medial substantia nigra and ventral tegmental area 


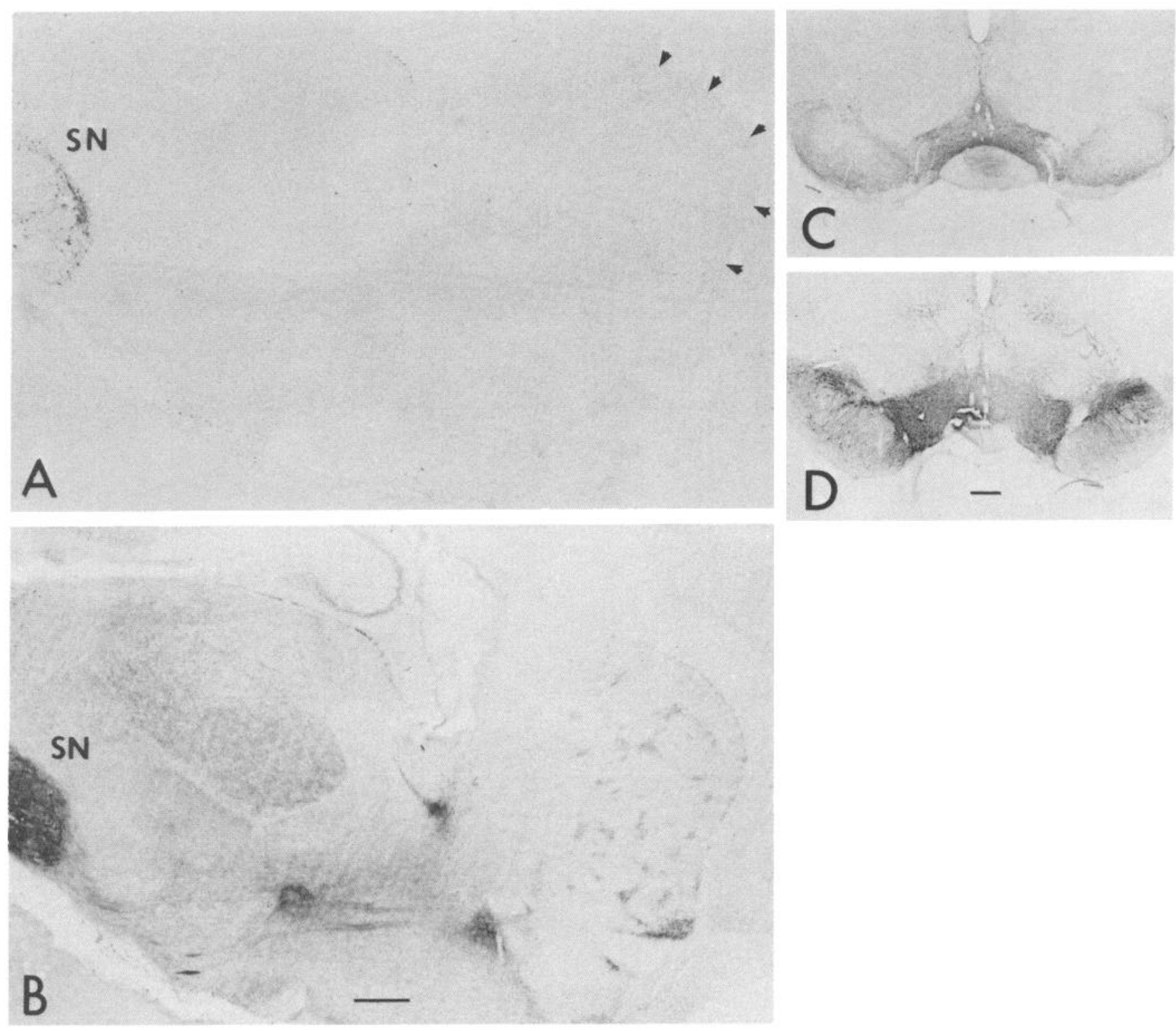

Figure 3. Postnatal distribution of TH- and SP-immunoreactive elements after prenatal 6-HDA. $A$, Note lack of TH-immunoreactive fibers in the striatum of a P2 rat (rostral extent of striatum in sagittal section outlined by arrowheads). This animal was perfused identically and tissue processed simultaneously with that shown in Figure $2 A$. B, SP-immunoreactive striatal patches and projections to the substantia nigra ( $S N$ ). Scale bar, $500 \mu \mathrm{m}$ for $A$ and $B$. C , TH-immunoreactive staining in a coronal section through the midbrain from a P18 rat treated prenatally with 6-HDA. $D$, Comparable section taken from a P18 control rat. Scale bar, $500 \mu \mathrm{m}$ for $C$ and $D$.

(Fig. 3C). Despite this massive loss of nigrostriatal DA projections, SP immunostaining of adjacent sections revealed the presence of distinctive clusters of SP-immunoreactive cells (Fig. $3 B$ ).

\section{Development of early patch markers (SP, AChE) in normal and perinatally 6-HDA-lesioned rats}

$P 6$. During the first postnatal week, DA patches remained visible in normal animals as dense areas of TH-immunoreactive fibers on a background of the developing matrix innervation (Fig. 4A). SP patches were characterized by clusters of immunoreactive neurons and associated dense fiber staining (Fig. 4B). Overlapping DA and SP patches were still obvious. AChE histochemistry revealed zones of dense stain that partially overlapped DA and SP patches in the lateral half of the striatum (Fig. $4 C$ ). Very few TH-immunoreactive fibers remained in the striatum of animals given successful pre- or postnatal 6-HDA injections (Fig. $4 D$ ). Despite this near-complete loss of patch DA innervation, the clustering of SP-immunoreactive cells appeared normal (Fig. $4 E$ ), and $A C h E$ histochemistry revealed the same dense zones in lateral striatum (Fig. $4 F$ ).

P12. At this age, patches of TH-immunoreactive fibers were no longer visible, because the matrix DA innervation filled in the striatum (Fig. 5A). Patches of SP-immunoreactive cells remained distinctive (Fig. $5 B$ ), but at older ages, cell bodies become increasingly harder to stain in the absence of colchicine treatment, leaving only dense aggregations of SP-immunoreactive fibers in the patch regions. AChE stain was now present throughout the striatum, and in the ventral aspect, the zones of 

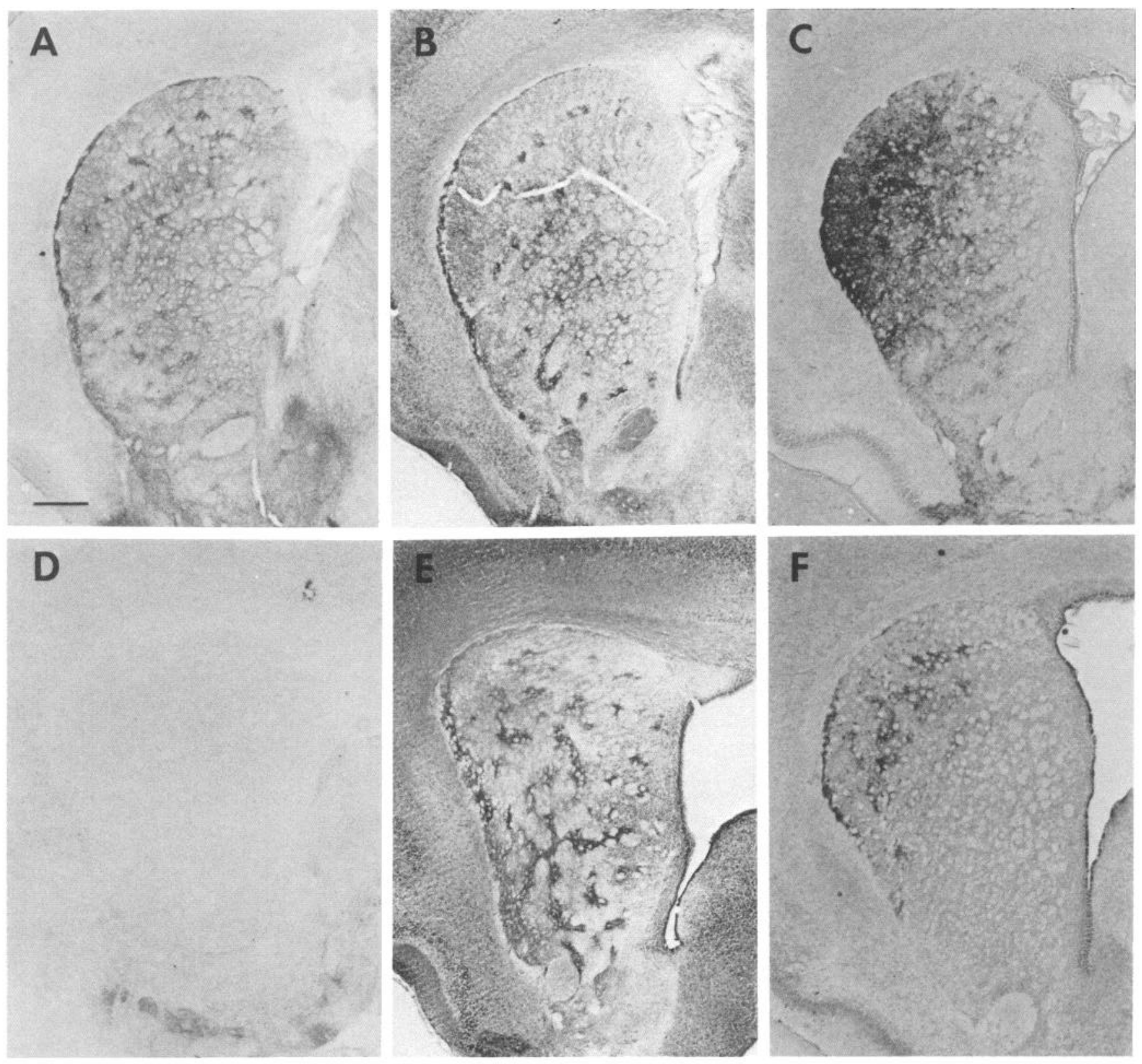

Figure 4. Striatal patch staining in coronal sections taken from normal $(A-C)$ and DA-depleted $(D-F)$ rats at P6. $A$, TH-immunoreactive patches are still visible at P6. B, SP-immunoreactive patches consisting of cell body and fiber staining. $C$, AChE-positive neuropil in the lateral striatum. $D$, TH immunocytochemistry reveals few DA fibers remaining in an animal given 6-HDA on P1. E, SP-immunoreactive patches remain distinctive after postnatal 6-HDA. F, AChE-positive neuropil. Small round "holes" throughout the striatum in this and subsequent figures are myelinated corticofugal fiber tracts. Scale bar, $500 \mu \mathrm{m}$ for $A-F$.

low AChE stain, termed "striosomes" by Graybiel and Ragsdale (1978), appeared on a more densely staining background (Fig. $5 C$ ). This transition was equally apparent in lesioned animals.

In several animals given prenatal 6-HDA injections and killed at P12 or later, DA lesions ranged from a complete bilateral denervation $(25 \%$ of surviving lesioned rats) to unilateral denervation $(6 \%)$ to a partial bilateral loss $(69 \%)$. In regions that were completely devoid of $\mathrm{TH}$-immunoreactive fibers, clusters of SP-immunoreactive cells were still apparent. In the case of incomplete lesions, surviving DA fibers were usually found to lie in distinctive patches within the dorsolateral striatum (Fig. $5 D$ ), though varying amounts of a more diffuse innervation were often present in the medial striatum, and sometimes in the dorsolateral striatum, as well. The patches of residual DA innervation showed considerable overlap with patches of SP-immunoreactive neurons in adjacent sections (Fig. $5 E, F$ ).

\section{Development of matrix markers (enkephalin, calbindin) in normal and perinatally 6-HDA-lesioned rats}

Satisfactory staining with 1-Enk antibodies was not obtained until near the end of the second postnatal week. At P18, cells immunoreactive for l-Enk were most readily stained and revealed a distinctive organization (see below). The antibody to calbindin, a characteristic marker of the matrix neurons (Gerfen et al., 1985), provided good staining at all ages, but exhibited a protracted developmental expression from ventrolateral to me- 

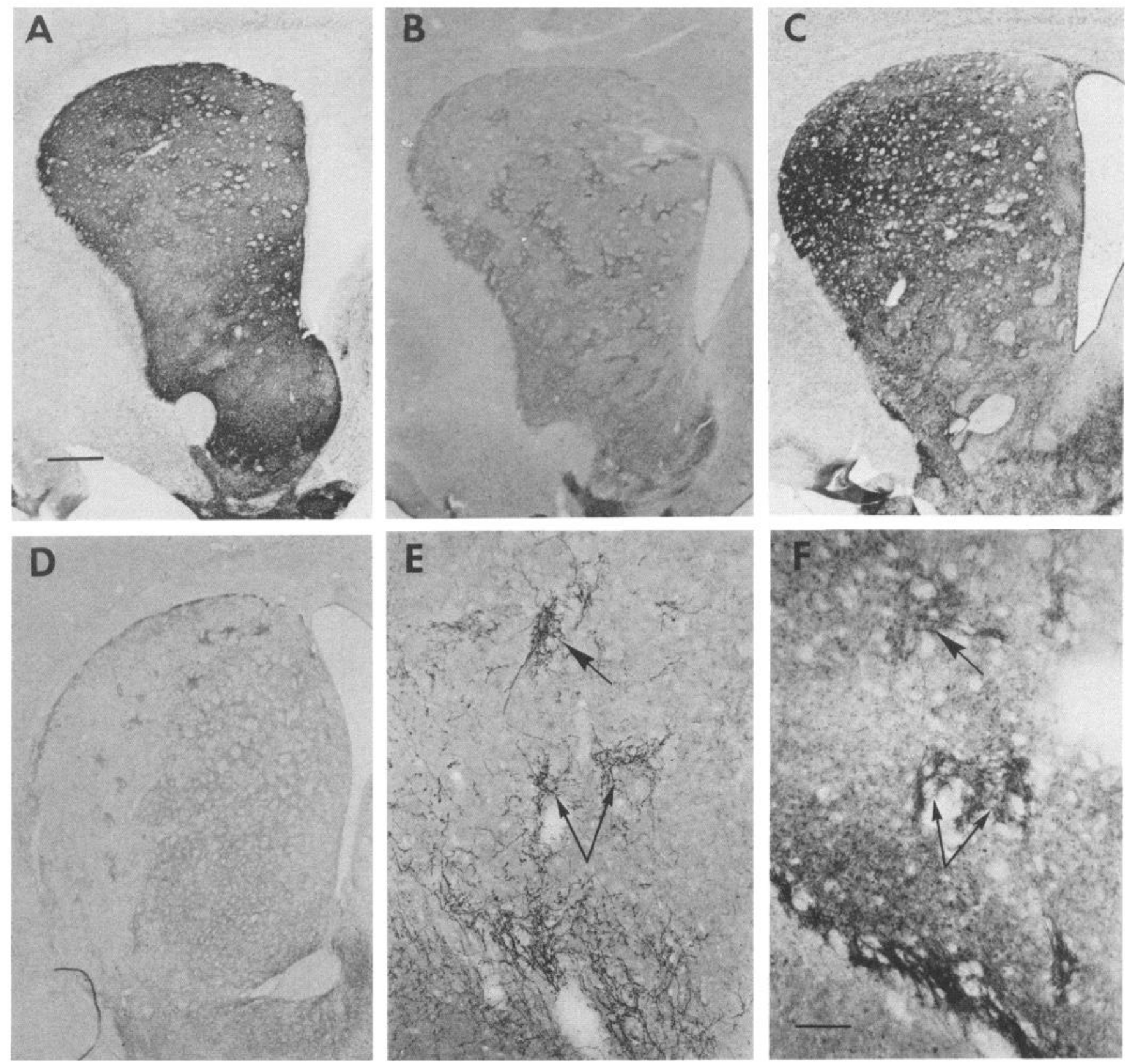

Figure 5. Striatal staining at P12 in normal brain $(A-C)$ and partially DA-depleted brain after prenatal 6-HDA treatment $(D-F)$. $A$, Homogeneous distribution of TH-immunoreactive fibers at P12. B, SP-immunoreactive patches. $C, \mathrm{AChE}$ stain showing transition from AChE-rich patches to AChE-poor striosomes. $D$, TH-immunoreactive fiber patches remaining in an animal that had received 6-HDA prenatally that resulted in an incomplete lesion. Scale bar, $500 \mu \mathrm{m}$ for $A-D$. $E$. High-power view of DA fiber patches. $F, \mathrm{SP}$-immunoreactive patches in a section adjacent to $E$. Arrows point to corresponding patches. Scale bar, $100 \mu \mathrm{m}$ for $E$ and $F$.

dial to dorsolateral portions of the striatum (see also Liu et al., 1989). For this reason, P18 was chosen as the earliest age to illustrate matrix localization of these 2 markers.

P18. At this age, the DA innervation in normal rats was homogeneously dense (Fig. $6 A$ ), and l-Enk-immunoreactive cell bodies were located in what appeared to be the matrix (Fig. $6 B$ ). A comparison of adjacent sections stained for 1-Enk and SP revealed that patches of SP-immunoreactive neurons were coincident with the patches devoid of 1-Enk-immunoreactive neurons (Fig. $7 A, B$ ). Neurons immunoreactive for calbindin were also confined to the matrix (Fig. $6 \mathrm{C}$ ), though at this age, neurons of the most dorsal aspect of the striatum are still not synthesizing appreciable amounts of the protein.

In animals treated with 6-HDA either pre- or postnatally, the same matrix localization of 1-Enk and calbindin-immunoreactive neurons was observed (Fig. $6 E, F, H, I$ ), despite the neartotal loss of DA innervation (Fig. $6 D, G$ ). Patches devoid of l-Enk-immunoreactive neurons still were found to correspond to patches of dense SP stain.

In older animals, l-Enk-immunoreactive neurons were not clearly visualized in the absence of colchicine treatment. Instead, fairly dense fiber staining was observed throughout the 

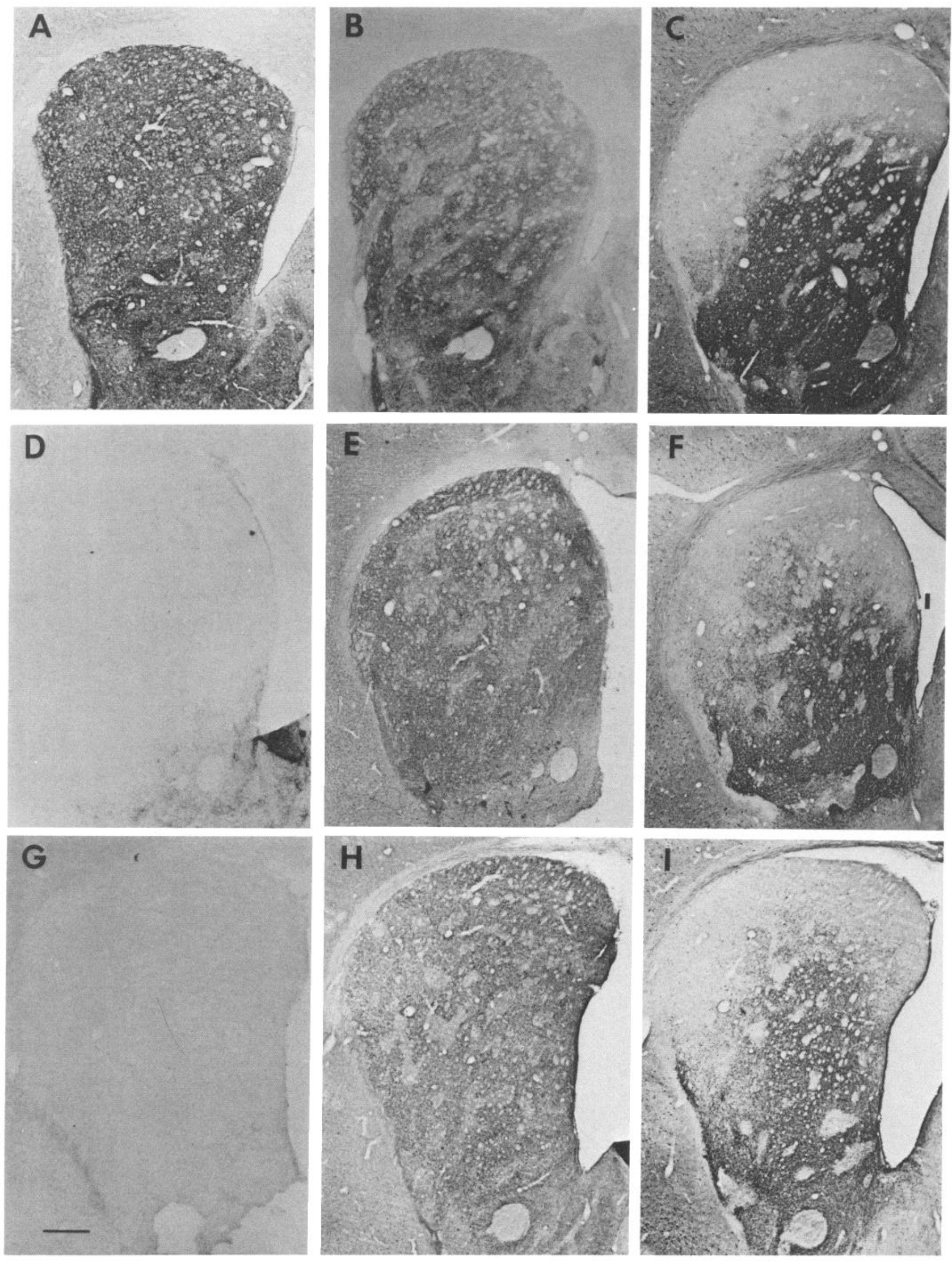

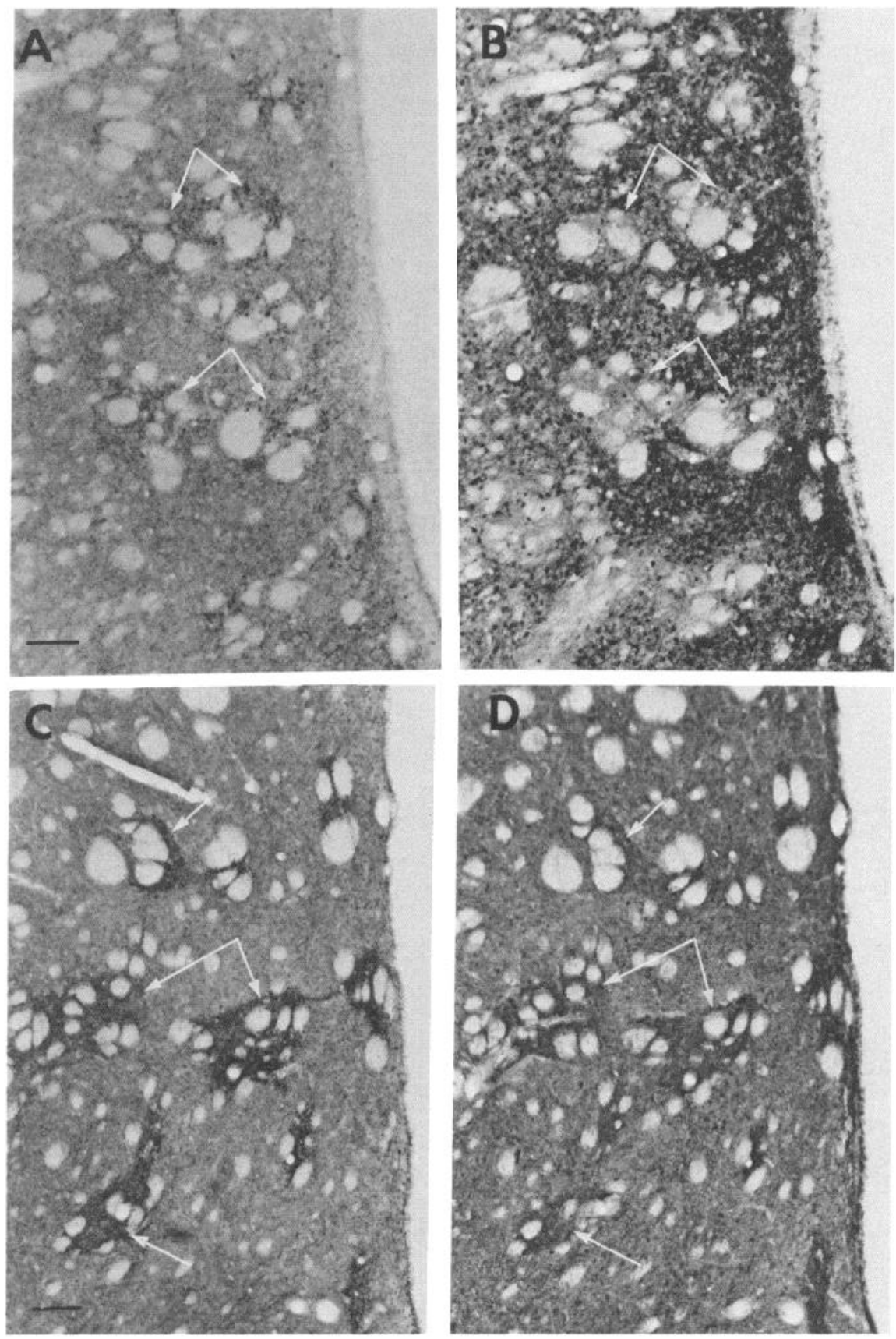

Figure 7. Correspondence of SP-immunoreactive patches $(A, C)$ and l-Enkimmunoreactive patches $(B, D)$. $A$, Patches of SP-immunoreactive cells in the medial striatum of a normal P18 rat. $B$, Patches devoid of 1-Enk-immunoreactive cells in a section adjacent to $A$. $C$, Patches of SP-immunoreactive fibers seen in the medial striatum of a normal adult. $D$, Patches of 1-Enk-immunoreactive fibers seen in a section adjacent to $C$. Arrows indicate corresponding zones. Scale bars, $100 \mu \mathrm{m}$ for A-D. striatum, with patches containing a higher density of l-Enkimmunoreactive fibers in the medial striatum (Fig. $7 D$ ). These patches were evident in both control and lesioned striata and were found to correspond to patches of SP-immunoreactive fibers (Fig. 7C). Calbindin-immunoreactive neurons were found throughout the striatum, confined to the matrix region.

\section{Discussion}

Developmental localization of immunocytochemically identified cell types to the patch or matrix compartment This study has provided a sequence of early ages comparing the development of staining for several different substances within

Figure 6. Matrix-associated immunoreactivity in coronal sections taken from normal $(A-C)$, prenatally DA-depleted $(D-F)$, or postnatally DAdepleted $(G-I)$ striatum at P18. $A, D$, and $G$, Compared to the homogeneous dense stain of a normal animal $(A)$, few TH-immunoreactive fibers remain in the striatum after prenatal $(D)$ or postnatal $(G)$ 6-HDA treatment. $B, E$, and $H, 1$-Enk-immunoreactive neurons predominantly found in the matrix surrounding patch regions in all animals. $C, F$, and $I$, Calbindin- $\mathrm{D}_{28 \mathrm{k}}$ immunoreactivity in the matrix of all animals. Scale bar, $500 \mu \mathrm{m}$ for $A-I$. 
the striatum of the rat and their localization to patch or matrix compartments. Substance P antisera stained clusters of striatal neurons at birth, which were largely coincident with the patches of DA fibers revealed by TH immunocytochemistry. Thus, SPimmunoreactive neurons are clearly a major component of the developing patch compartment (see also Boylan et al., 1990; Zahm et al., 1990), as they are in the patches of the mature striatum (Beckstead and Kersey, 1985; Penny et al., 1986). Projections of these neurons reach the substantia nigra early in development, where they are in a position to contact the DA cell bodies (Fishell and van der Kooy, 1989). Thus, this earlyforming DA-SP circuit may provide a stable foundation for further development of the patch/matrix organization. The ability to stain cell bodies containing the peptide was greatly diminished during the third postnatal week, however, so that SPimmunoreactive patches consisted of terminals only, against a background of lower-density terminal staining. Thus, a final picture emerges of SP neurons relatively confined to the patch regions and giving rise to a concentration of local collaterals, while at the same time providing innervation to the matrix.

The immunocytochemical localization of enkephalin at different ages provided a different picture. Reliable staining could not be achieved until the end of the second postnatal week, at which timc immunoreactive cell bodies were distributed throughout the striatum, with the exception of patches devoid of l-Enk-immunoreactive cells. This distribution was very distinctive during the third postnatal week, when it became clear that l-Enk-immunoreactive neurons were confined to the matrix compartment. This localization was confirmed by the matching of 1-Enk-poor patches with SP-rich patches in adjacent sections. Beyond the third postnatal week, the ability to stain cell bodies was again lost, leaving instead a rather dense plexus of 1-Enkimmunoreactive terminal staining. Patches of dense terminal staining were present, primarily along the medial border, and frequently were in alignment with SP-rich patches. It is this latter picture of dense fiber patches that has led most researchers to consider enkephalin a marker of the striatal patch region (Graybiel et al., 1981b; Gerfen, 1984). However, Graybiel and Chesselet (1984) had previously recognized the localization of enkephalin-immunoreactive cell bodies to the matrix, as revealed by altering the conditions of the immunocytochemical procedure. The present findings underscore the notion that enkephalin-immunoreactive neurons are primarily localized to the matrix, though they may make especially dense projections to the patches. This would also suggest that enkephalin may provide another link between the 2 compartments, as has been suggested for somatostatin neurons (Gerfen, 1984).

The shift from cell body to fiber staining as revealed by immunocytochemical means during the third postnatal week points to a major metabolic change in the peptidergic neurons at this time. The loss of peptidergic staining with age has previously been attributed to relatively high levels of activity and axonal transport and the inability to synthesize an excess of peptide for storage in the cell body (Inagaki et al., 1982). Several factors may play a role in this conversion in the striatum. Substance $P$ is synthesized very early within neurons of the patch compartment; these neurons are born earlier than neurons of the matrix (van der Kooy and Fishell, 1987), are the first to send axons to the ventral mesencephalon (Fishell and van der Kooy, 1987), and are otherwise more mature than their matrix counterparts (Snyder-Keller, 1988). The early distribution of DA and corticostriatal afferents to these patch regions, where $D_{1}$ receptors are also localized (Murrin and Zeng, 1989), suggests that SP neurons are in a position to receive an early activating influence from dopaminergic and perhaps also glutamatergic terminals. This increasing demand leads to a reduction in stored peptides and a loss of SP immunostaining within the cell body at an early age. Enkephalin-immunoreactive neurons are localized to the matrix and are presumably less mature as a result, receiving activating inputs later in development. Enkcphalin immunoreactivity in striatal cell bodies is at its zenith during the third postnatal week. Also at this time, there is a dramatic increase in the density of $D_{1}$ receptors within the matrix (Rao et al., 1989), and this may be one of several developments that interact to alter peptide distribution within striatal neurons of the 2 compartments.

In situ hybridization studies have demonstrated the existence of mRNA for SP, enkephalin, and dynorphin in neurons of both the patch and the matrix compartments (Chesselet et al., 1987; Gerfen and Young, 1988), though not necessarily in equal amounts. Patch neurons, for example, do contain more SP mRNA than their matrix counterparts (Chesselet and Robbins, 1989). More immunoreactive peptide in one compartment could reflect either increased synthesis or stability of mRNA, so that more peptide is synthesized, perhaps combined with decreased turnover of the peptide, so that more is stored in the cell body (Chesselet and Robbins, 1989). In any case, the consistency with which immunocytochemical analyses reveal differential patch and matrix staining suggests that important functional differences exist between the 2 populations of neurons.

Calbindin antibodies are probably the most reproducible means of demonstrating the existence of patch and matrix compartments via immunocytochemistry in the adult, despite the fact that the significance of calbindin's presence within striatal neurons is largely unknown (DiFiglia et al., 1989). This protein is found exclusively within striatal neurons of the matrix compartment, and also in nigral projections to the matrix (Gerfen et al., 1985, 1987). Developmentally, however, its expression in matrix neurons located in different topographical regions of the striatum shows a variable time course. During the first postnatal week, a small number of calbindin-immunoreactive neurons were located ventrolaterally, and as development proceeds, more medial neurons expressed the protein (see also Liu et al., 1989). Even during the third to fourth postnatal week, a dorsal zone of non-calbindin-immunoreactive matrix neurons is evident. Nevertheless, within these developmental constraints, the patches devoid of calbindin staining remain distinctive well into adulthood.

The developmental transition from a patchy distribution of AChE stain to an adult pattern of dense stain interspersed with zones of low AChE has heen well characterized (Butcher and Hodge, 1976; Graybiel, 1984). Whereas the presence of AChE is not an unequivocal index of cholinergic neurons, the heterogeneous pattern of AChE stain in adult animals corresponds to inhomogeneities in immunohistochemical staining for choline acetyltransferase, a more specific marker (Graybiel et al., 1986). Darkly stained, AChE-reactive cell bodies were readily apparent in material examined here from younger animals, and these cells are likely to be ACh-containing neurons. Finally, the persistence of a normal pattern of AChE stain in animals sustaining early DA-depleting lesions suggests that little of the enzyme is associated with DA terminals, as has been suggested (Butcher and Hodge, 1976; Graybiel, 1984).

The degree of overlap between patches of SP-immunoreactive 
cell bodies and cellular patches lacking 1-Enk and calbindin immunoreactivity was found to be considerable at the third postnatal week, when cell bodies could be reliably identified with all antibodies. This overlap continued into adulthood, but assumed a picture of patches of dense SP-immunoreactive fibers that overlapped with patches of dense l-Enk-immunoreactive fibers. Preliminary findings in adult rats revealed a correspondence between peptidergic fiber patches and patches of cells lacking calbindin immunoreactivity, which also concentrate fluoro-gold after an intrastriatal injection in infancy (see SnyderKeller, 1988). Thus, the patches delineated by each antibody are nearly always the same groupings of neurons, but a precise determination of what percentage are SP-immunoreactive has yet to be accomplished. The extent to which a less than complete overlap can bc attributed to the use of adjacent, rather than identical, sections remains to be determined. A computer-assisted morphometric study revealed a maximal incidence of overlap of $40 \%$ when adjacent $50-\mu \mathrm{m}$ sections were analyzed, even when comparing sections stained with the same antibody (Agnati et al., 1988).

\section{Lack of effect of perinatal DA depletion on striatal organization}

The early appearance of DA afferents within the striatum, and their distribution into patches, led several researchers to suggest that DA may provide a guiding influence for the formation of the patch/matrix organization (Graybiel, 1984; Lanca et al., 1986; Voorn et al., 1988). The early removal of DA innervation has previously been shown to result in an altered distribution of another set of striatal afferents, those coming from the dorsal raphe (Snyder et al., 1986; Luthman et al., 1987), representing an anatomical rearrangement following neonatal DA depletion that does not occur following DA-depleting lesions in adulthood (Snyder et al., 1986). Thus, the early presence of DA afferents in their normally patchy distribution may be important for anatomical development of the striatum. Further evidence for the role of DA in the formation of striatal compartments comes from studies correlating the first appearance of DA fibcrs into patches with the patchy distribution of other elements. The formation of patches of opiate-hinding sites (Moon Edley and Herkenham, 1984) and corticostriatal afferents (Goldman-Rakic, 1981), both of which are present initially in a homogeneous distribution, occurs 1-2 d after the formation of DA patches. However, patches revealed by other postsynaptic markers appear to precede the emergence of DA patches (Foster et al., 1987; Newman-Gage and Graybiel, 1988).

The present data indicate that DA is not a necessary formative influence during late prenatal and early postnatal development. Prenatal 6-HDA injections, which resulted in the destruction of DA terminals prior to the time that DA patches are formed, did not lead to any observable reorganization of the striatum, as measured by SP, 1-Enk, and calbindin immunocytochemistry and $\mathrm{AChE}$ histochemistry. Clear patterns were retained and exhibited the same degree of overlap as in normal animals, despite the fact that a near-complete destruction of DA fibers was obtained in the best cases. The same normal distribution of striatal neurons was found after postnatal lesions, which were more specific given the use of desmethylimipramine to block uptake of the 6-HDA into noradrenergic neurons. In both groups of animals, TH immunocytochemistry was used to reveal the distribution of remaining DA fibers in order to verify that cellular patches still developed in regions totally devoid of DA innervation. Thus, the results reported here suggest that the formation of DA patches is not necessary for the initial distribution of striatal neurons into the patch/matrix compartments. However, it remains a possibility that the earliest DA fibers to reach the striatum somehow influence cells to become patch neurons, even prior to the occurrence of distinctive fibcr clustering. A test of this hypothesis would require lesions even earlier in development, or the demonstration that none of the cellular markers that eventually become confined to the patch compartment have done so by the time of the lesion. Nevertheless, the present findings indicate that the presence of DA patches during the late fetal period is not required for the subsequent emergence of cellular patches or for the maintenance of this compartmentalization.

The close association between immature DA terminals and patches of striatal neurons visualized by ${ }^{3} \mathrm{H}$-thymidine autoradiography (Graybiel, 1984), retrograde labeling after nigral injections (Fishell and van der Kooy, 1987), fluoro-gold labeling after intrastriatal injection (Snyder-Keller, 1988), or the presence of opiate-binding sites (Moon Edley and Herkenham, 1984) cannot be refuted. The immunocytochemical evidence reported here suggests that these patches are predominantly composed of SP-immunoreactive neurons. Patches of DA terminals were found to overlap with patches of SP-immunoreactive neurons during the first postnatal week. However, this overlap was usually not complete in adjacent sections and was confounded by the fact that $\mathrm{TH}$-immunoreactive patches were most distinct in the dorsal striatum, whereas SP immunostaining revealed the clearest patches ventrally. A striking overlap was seen in animals prenatally treated with 6-HDA but incurring subtotal DA depletions, which were particularly frequent if less than $110 \mu \mathrm{g}$ 6-HDA was injected. In these cases, the remaining DA fibers distributed into patches that were often more distinctive than those seen in the normal animal, due to the loss of surrounding matrix innervation. The unmistakable colocalization of patches of DA terminals with patches of SP-immunoreactive cells in these animals may be explained as a relative resistance of patchprojecting DA fibers to the neurotoxic effects of 6-HDA. This is unlikely, however, because the capacity for uptake should be superior in more mature fibers, which at the time of the injection at E17-18 would be predominantly DA fibers destined to be patch associated. Indeed, the direct intrastriatal administration of 6-HDA into neonatal rats has been shown to result in the selective loss of patch-directed DA fibers (Gerfen et al., 1987). Thus, neurons with terminals already in the striatum should exhibit a relative vulnerability to the damaging effects of 6-HDA. A more likely explanation for the localization of spared fibers to the patch regions is that surviving DA neurons, which normally would not have innervated patch regions, now grow selectively to the patches. This rerouting of DA afferents will have to be tested by determining the intranigral location of cell bodies giving rise to these fibers, which is different in the case of patchversus matrix-directed DA afferents in normal animals (Gerfen et al., 1987; Jimenez-Castellanos and Graybiel, 1987).

Previous attempts to disrupt dopaminergic influence on the developing striatum have led to equivocal results. Chronic haloperidol administration prenatally produced a decrease in the density of opiate-binding sites without affecting their patchy distribution (Moon, 1984; van der Kooy, 1984). Transplantation of embryonic striata into extrastriatal sites resulted in the development of less distinct patches of opiate-binding sites (Lanca et al., 1986). Clear patches of immunoreactive elements are 
observed following striatostriatal transplantation; however, in this case, DA fibers are observed to grow into the transplant in a patchy fashion (Isacson et al., 1987). Other studies using postnatal 6-HDA administration have assessed changes in peptide content or mRNA level in the absence of data concerning their anatomical distribution. Sivam and coworkers (Sivam et al., 1987) found an increase in mRNA for enkephalin and a decrease in SP mRNA, the latter change being specific to DA depletions early in life. Other reported effects of neonatal 6-HDA treatment include a reduction in opiate receptor binding (Gerfen et al., 1987) and $D_{1}$ receptor binding (Gelbard et al., 1989) and a change in the morphology of individual enkephalin- and GADimmunoreactive neurons (Pickel et al., 1986). Thus, numerous changes may be occurring in the physiology and function of striatal neurons that are deprived of their normal DA innervation, in the absence of overall changes in the anatomical distribution of specific peptide-containing cells.

Other factors contributing to the development of striatal patch/ matrix organization

Much evidence has accrued for the selective association of striatal patch neurons with one another during development and the significance of this event as the foundation for the patch/ matrix organization. First, striatal patch neurons are born earlier than matrix neurons (Graybiel and Hickey, 1982; Bayer, 1984; Marchand and Lajoie, 1986; van der Kooy and Fishell, 1987) and send projections to the substantia nigra prior to the time of genesis of most striatal matrix neurons (Fishell and van der Kooy, 1989). One proposed mechanism is that cells born later isolate the early cells as they stream through the striatum (Marchand and Lajoie, 1986; Fishell and van der Kooy, 1987). However, the segregation may involve more than mechanical forces; experiments with cultured striatal cells suggest that chemospecificity may play a role as well. Krushel and coworkers (Krushel et al., 1989) demonstrated that, following dissociation of the E15 or E20 rat striata, patch neurons (identified by their ${ }^{3} \mathrm{H}$ thymidine labeling after an injection at E13) selectively aggregated with one another. The cellular markers $\mathrm{Ca}^{2+} / \mathrm{CAM}-\mathrm{de}-$ pendent protein kinase II (Newman-Gage and Graybiel, 1988) and DARPP-32 (Foster et al., 1987) show a patchy distribution prenatally, and the developmental expression of DARPP-32 in striatal cultures is unchanged by the presence of co-cultured DA neurons (Ehrlich et al., 1990).

Afferents other than DA nigrostriatal projections may play a role in the formation of the patch/matrix organization. The earliest-arriving corticostriatal projections from the frontal cortex are distributed into patches (Goldman-Rakic, 1981; Gerfen, 1984). These afferents arise from the cells of the deep layers that are generated earliest (Gerfen, 1989), and cortical neurons of the deep layers may share a common early progenitor with striatal patch neurons (Fishell et al., 1989). It remains to be seen whether specific chemoaffinities play a role in the association of patch striatal neurons and afferent populations, or whether it is simply a matter of timing: the earliest fibers coming from both the cortex and the nigra enter the striatal primordia at an age when the cells present there are almost exclusively patch neurons. During the first postnatal week, DA afferents overlap with patches of neurons that stain heavily for Timm's reaction, which has been associated with the presence of zinc, and may indicate the storage of NGF propeptide within these cells (Vincent and Semba, 1989).

The available evidence suggests that striatal neurons that form the patches have a propensity to associate with one another. The development of patches of DA afferents, though probably important in modulating the expression of substances within striatal neurons, is likely to occur secondary to cellular clustering. The degree to which the compartmentalization of cells is preprogrammed, or simply determined by the timing of cell birth and migration, has yet to be determined. Other factors such as the cordoning off of patch regions by glia (Steindler et al., 1988) and a greater incidence of dye coupling between immature striatal neurons (Walsh et al., 1989) may play a role in stabilizing this structure. Multiple influences may interact to guide the initial formation of patches, which then become a stable structural feature of the striatum.

\section{References}

Agnati LF, Fuxe K, Zoli M, Ferraguti F, Benfenati F, Ouimet CC, Walaas SI, Hemmings HC Jr, Goldstein M, Greengard P (1988) Morphometrical evidence for a complex organization of tyrosine hydroxylase-, enkephalin- and DARPP-32-like immunoreactive patches and their codistribution at three rostrocaudal levels in the rat ncostriatum. Neuroscience 27:785-797.

Bayer S (1984) Neurogenesis in the rat neostriatum. Int J Dev Neurosci 2:163-175.

Beckstead RM, Kersey KS (1985) Immunohistochemical demonstration of differential substance P-, met-enkephalin-, and glutamic acid decarboxylase-containing cell body and axon distributions in the corpus striatum of the cat. J Comp Neurol 232:481-498.

Boylan MK, Levine MS, Buchwald NA, Fisher RS (1990) Patterns of tachykinin expression and localization in developing feline neostriatum. J Comp Neurol 293:151-163.

Breese GR, Traylor TD (1971) Depletion of brain noradrenaline and dopamine by 6-hydroxydopamine. Br J Pharmacol 42:88-99.

Butcher LL, Hodge GK (1976) Postnatal development of acetylcholinesterase in the caudate-putamen nucleus and substantia nigra of rats. Brain Res 106:223-240.

Chesselet M-F, Robbins E (1989) Regional differences in substance P-like immunoreactivity in the striatum correlate with levels of preprotachykinin mRNA. Neurosci Lett 96:47-53.

Chesselet M-F, Weiss L, Wuenschell C, Tobin AJ, Affolter H-U (1987) Comparative distribution of $m$ RNAs for glutamic acid decarboxylase, tyrosine hydroxylase, and tachykinins in the basal ganglia: an in situ hybridization study in the rodent brain. J Comp Neurol 262:125140.

DiFiglia M, Christakos S, Aronin N (1989) Ultrastructural localization of immunoreactive calbindin- $D_{28 \mathrm{k}}$ in the rat and monkey basal ganglia, including subcellular distribution with colloidal gold labeling. J Comp Neurol 279:653-665.

Ehrlich ME, Rosen NL, Kurihara T, Shalaby IA, Greengard P (1990) DARPP-32 development in the caudate nucleus is independent of afferent input from the substantia nigra. Dev Brain Res 54:257-263.

Fishell G, van der Kooy D (1987) Patlem formation in the striatum: developmental changes in the distribution of striatonigral neurons. $J$ Neurosci 7:1969-1978.

Fishell G, van der Kooy D (1989) Pattern formation in the striatum: developmental changes in the distribution of striatonigral projections. Dev Brain Res 45:239-255.

Fishell G, Rossant J, van der Kooy D (1989) Neuronal lineages in chimeric forebrain are compartmentally segregated. Soc Neurosci Abstr 15:22.

Foster GA, Schultzberg M, Hokfelt T, Goldstein M, Hemmings HC Jr, Ouimet CC, Walaas SI, Greengard P (1987) Development of a dopamine- and cyclic adenosine $3^{\prime}: 5^{\prime}$-monophosphatc-rcgulated phosphoprotein (DARPP-32) in the prenatal rat central nervous system, and its relationship to the arrival of presumptive dopaminergic innervation. J Neurosci 7:1994-2018.

Gelbard HA, Teicher MH, Gallitano AC, Zore J, Faedda G, Baldessarini RJ (1989) Postnatal development of dopamine D-1 receptors may require D-1 receptor stimulation. Soc Neurosci Abstr 15:170.

Gerfen CR (1984) The neostriatal mosaic: compartmentalization of corticostriatal input and striatonigral output systems. Nature 311: $461-463$.

Gerfen CR (1985) The neostriatal mosaic. I. Compartmental orga- 
nization of projections from the striatum to the substantia nigra in the rat. J Comp Neurol 236:454-476.

Gerfen CR (1988) Synaptic organization of the striatum. J. Electron Microsc Tech 10:265-281

Gerfen CR (1989) The neostriatal mosaic: striatal patch-matrix organization is related to cortical lamination. Science $246: 385-388$.

Gerfen CR, Young WS III (1988) Distribution of striatonigral and striatopallidal peptidergic neurons in both patch and matrix compartments: an in situ hybridization histochemistry and fluorescent retrograde tracing study. Brain Res 460:161-167.

Gerfen CR, Baimbridge KG, Miller JJ (1985) The neostriatal mosaic: compartmental distribution of calcium-binding protein and parvalbumin in the basal ganglia of the rat and monkey. Proc Nat1 Acad Sci USA 82:8780-8784.

Gerfen CR, Baimbridge KG, Thibault J (1987) The neostriatal mosaic: III. Biochemical and developmental dissociation of patch-matrix mesostriatal systems. J Neurosci 7:3935-3944.

Goldman-Rakic PS (1981) Prenatal formation of cortical input and development of cytoarchitectonic compartments in the neostriatum of the rhesus monkey. J Neurosci 1:721-735.

Graybiel AM (1984) Correspondence hetween the dopamine islands and striosomes of the mammalian striatum. Neuroscience 13:11571187.

Graybiel AM, Chesselet M-F (1984) Compartmental distribution of striatal cell bodies expressing [met]enkephalin-like immunoreactivity. Proc Natl Acad Sci USA 81:7980-7984.

Graybiel AM, Hickey TL (1982) Chemospecificity of ontogenetic units in the striatum: demonstration by combining ${ }^{3} \mathrm{H}$-thymidine neuronography and histochemical staining. Proc Natl Acad Sci USA 79:198202.

Graybiel AM, Ragsdale CW Jr (1978) Histochemically distinct compartments in the striatum of human, monkey and cat demonstrated by acetylcholinesterase staining. Proc Natl Acad Sci USA 75:57235726.

Graybiel AM, Ragsdale CW Jr (1983) Biochemical anatomy of the striatum. In: Chemical neuroanatomy (Emson PC, ed), pp 427-504. New York: Raven.

Graybiel $\Lambda$ M, Baughman RW, Eckenstein F (1986) Cholinergic neuropil of the striatum observes striosomal boundaries. Nature 323 : $625-627$.

Graybiel AM, Pickel VM, Joh TH, Reis DJ, Ragsdale CW Jr (1981a) Direct demonstration of a correspondence between the dopamine islands and acetylcholinesterase patches in the developing striatum. Proc Natl Acad Sci USA 78:5871-5875.

Graybiel AM, Ragsdale CW Jr, Yoneoka ES, Elde RP (1981b) An immunohistochemical study of enkephalins and other neuropeptides in the striatum of the cat with evidence that the opiate receptors are arranged to form mosaic patterns in register with the striosomal compartments visible by acetylcholinesterase staining. Neuroscience 6 : 377-397.

Inagaki S, Sakanaka M, Shiosaka S, Senba E, Takatsuki K, Takagi H, Kawai Y, Minagawa H, Tohyama M (1982) Ontogeny of substance P-containing neuron system of the rat: immunohistochemical analysis-I. Forebrain and upper brain stem. Neuroscience 7:251-277.

Isacson O, Dawbarn D, Brundin P, Gage FH, Emson PC, Björklund A (1987) Neural grafting in a rat model of Huntington's disease: striosomal-like organization of striatal grafts as revealed by acetylcholinesterase histochemistry, immunocytochemistry and receptor autoradiography. Neuroscience 22:481-497.

Jimenez-Castellanos J, Graybiel AM (1987) Subdivisions of the dopamine-containing A8-A9-A10 complex identified by their differential mesostriatal innervation of striosomes and extrastriosomal matrix. Neuroscience 23:223-242.

Krushel LA, Connolly JA, van der Kooy D (1989) Pattern formation in the mammalian forebrain: patch neurons from the rat striatum selectively reassociate in vitro. Dev Brain Res 47:137-142.

Lanca AJ, Boyd S, Kolb B, van der Kooy D (1986) The development of a patchy organization of the rat striatum. Dev Brain Res 27:1-10.

Levey AI, Wainer BH, Mufson EJ, Mesulam M-M (1983) Co-localization of acetylcholinesterase and choline acetyltransferase in the rat cerebrum. Neuroscience 9:9-22.

Liu F-C, Graybiel AM, Emson PC, Gerfen C (1989) Developmental expression of calbindin-28kD in striatum of postnatal rats. Soc Neurosci Abstr 15:909.
Luthman J, Bolioli B, Tsutsumi T, Verhofstad A, Jonsson G (1987) Sprouting of striatal serotonin nerve terminals following selective lesions of nigro-striatal dopamine neurons in neonatal rat. Brain Res Bull 19:269-274.

Marchand R, Lajoie L (1986) Histogenesis of the striopallidal system in the rat. Neurogenesis of its neurons. Neuroscience 17:573-590.

Moon SL (1984) Prenatal haloperidol alters striatal dopamine and opiate receptors. Brain Res 323:109-113.

Moon Edley S, Herkenham M (1984) Comparative development of striatal opiate receptors and dopamine revealed by autoradiography and histofluorescence. Brain Res 305:27-42.

Murrin LC, Ferrer JR (1984) Ontogeny of the rat striatum: correspondence of dopamine terminals, opiate receptors and acetylcholinesterase. Neurosci Lett 47:155-160.

Murrin LC, Zeng W (1989) Dopamine $D_{1}$ receptor development in the rat striatum: early localization in striosomes. Brain Res 480:170177.

Nastuk MA, Graybiel AM (1985) Patterns of muscarinic cholinergic binding in the striatum and their relation to dopamine islands and striosomes. J Comp Neurol 237:176-194.

Newman-Gage H, Graybiel AM (1988) Expression of calcium/calmodulin-dependent protein kinase in relation to dopamine islands and synaptic maturation in the cat striatum. J Neurosci 8:3360-3375.

Ni L, Jonakait GM (1988) Development of substance P-containing neurons in the central nervous system in mice: an immunocytochemical study. J Comp Neurol 275:493-510.

Olson L, Seiger A, Fuxe K (1972) Heterogeneity of striatal and limbic dopamine innervation: highly fluorescent islands in developing and adult rats. Brain Res 44:283-288.

Penny GR, Afsharpour S, Kitai ST (1986) The glutamate decarboxylase-, leucine enkephalin-, methionine enkephalin- and substance P-immunoreactive neurons in the neostriatum of the rat and cat: evidence for partial population overlap. Neuroscience 17:1011-1045.

Pickel VM, Carson M, Chan J, Joh TH, Smith D (1986) Alterations in target neurons in the adult rat neostriatum following neonatal destruction of dopaminergic afferents. Soc Neurosci Abstr 12:379.

Rao PA, Molinoff PB, Joyce JN (1989) Ontogeny of the D-1 and D-2 subtypes of dopamine receptor in rat basal ganglia: a quantitative autoradiographic study. Soc Neurosci Abstr 15:171.

Sivam SP, Breese GR, Krause JE, Napier TC, Mueller RA, Hong JS (1987) Neonatal and adult 6-hydroxydopamine-induced lesion differentially alter tachykinin and enkephalin gene expression. J Neurochem 49:1623-1633.

Snyder AM, Zigmond MJ, Lund RD (1986) Sprouting of serotonergic afferents into striatum after dopamine-depleting lesions in infant rats: a retrograde transport and immunocytochemical study. J Comp Neurol 245:274-281.

Snyder-Keller AM (1988) Fluoro-gold reveals patches of striatal neurons during development. Neurosci Lett 91:136-141.

Stachowiak MK, Bruno JP, Snyder AM, Stricker EM, Zigmond MJ (1984) Apparent sprouting of striatal serotonergic terminals after dopamine-depleting brain lesions in neonatal rats. Brain Res 291 164-167.

Steindler DA, O'Brien TF, Cooper NGF (1988) Glycoconjugate boundaries during early postnatal development of the neostriatal mosaic. J Comp Neurol 267:357-369.

van der Kooy D (1984) Developmental relationships between opiate receptors and dopamine in the formation of caudate-putamen patches. Dev Brain Res 14:300-303.

van der Kooy D, Fishell G (1987) Neuronal birthdate underlies the development of striatal compartments. Brain Res 401:155-161.

Vincent SR, Semba K (1989) A heavy metal marker of the developing striatum. Dev Brain Res 45:155-159.

Voorn P, Kalsbeek A, Jorritsma-Byham B, Groenewegen HJ (1988) The pre- and postnatal development of the dopaminergic cell groups in the ventral mesencephalon and the dopaminergic innervation of the striatum of the rat. Neuroscience 25:857-887.

Walsh JP, Cepeda C, Hull CD, Fisher RS, Levine MS, Buchwald NA (1989) Dye-coupling in the neostriatum of the rat: II. Decreased coupling between neurons during development. Synapse 4:238-247.

Zahm DS, Eggerman KW, Sprung RF, Wesche DE, Payne E (1990) Postnatal development of striatal neurotensin immunoreactivity in relation to clusters of substance $P$ immunoreactive neurons and the "dopamine islands" in the rat. J Comp Neurol 296:403-414. 